\title{
PENGEMBANGAN SISTEM DOWNLINK DATA ADAPTIF UNTUK PENINGKATAN DAYA JELAJAH PESAWAT TANPA AWAK
}

\author{
Agus Basukesti ${ }^{1}$, Bangga Dirgantara Adiputra ${ }^{2}$ \\ ${ }^{1}$ Program Studi Teknik Elektro Sekolah Tinggi Teknologi Adisutjipto \\ ${ }^{2}$ Program Studi Teknik Penerbangan Sekolah Tinggi Teknologi Adisutjipto \\ 1agus_basukesti@yahoo.com \\ 2bdirgantara@stta.ac.id
}

\begin{abstract}
The main challenge for the development of unmanned aircraft today is the cruising range of unmanned aircraft. One of the causes of limited cruising range is the weakness of the communication system between aircraft and ground station. In this study designed a system of data downlink integrated with adaptive control so that it can increase cruising range from unmanned aircraft. The method used in this research is the experimental method to get the design and pilot plan downlink data system combined with adaptive control to create intelligent data downlink device that can increase cruising range unmanned aircraft. From this research found that Kalman Filter is the best algorithm used in designing an adaptive downlink system.
\end{abstract}

keywords: unmanned aircraft, cruising, adaptive, downlink

\begin{abstract}
Abstrak
Tantangan utama pengembangan pesawat tanpa awak saat ini adalah daya jelajah dari pesawat tanpa awak. Salah satu penyebab terbatasnya daya jelajah adalah lemahnya sistem komunikasi antara pesawat dan ground station. Dalam penelitian ini dirancang sistem downlink data yang diintegerasikan dengan kendali adaptif sehingga dapat menambah daya jelajah dari pesawat tanpa awak. Metode yang digunakan dalam penelitian ini adalah metode eksperimen untuk mendapatkan rancangan dan pilot plan sistem downlink data yang dikombinasikan dengan kendali adaptif sehingga tercipta perangkat downlink data cerdas yang dapat meningkatkan daya jelajah pesawat tanpa awak. Dari penelitian ini didapatkan bahwa Kalman Filter merupakan algoritma terbaik yang digunakan dalam mendesain sebuah sistem downlink adaptif.

kata kunci : pesawat tanpa awak, jelajah, adaptif, downlink
\end{abstract}

\section{Pendahuluan}

Pesawat tanpa awak merupakan salah satu topik penelitian yang sedang menarik untuk dikembangkan dalam 10 tahun terakhir. Dalam aplikasinya, pesawat tanpa awak tidak hanya digunakan untuk keperluan militer, tetapi juga untuk keperluan sipil seperti pemotretan, pemantauan, bahkan menjadi salah satu bagian dalam mitigasi bencana. Effisiensi biaya dan keselamatan merupakan nilai lebih yang ditawarkan oleh pesawat tanpa awak. Dengan demikian pengembangan pesawat tanpa awak menarik untuk dilakukan mengingat peran strategis dari pesawat tanpa awak.

Secara umum pesawat tanpa awak terdiri dari sistem mekanik dan sistem elektronik (avionic). Sistem mekanik adalah sistem pada pesawat tanpa awak yang berpengaruh terhadap gerakan pada fisik pesawat. Sedangkan sistem elektronik (avionic) adalah sistem pada pesawat tanpa awak yang memiliki fungsi menjalankan algoritma dan navigasi pada pesawat tanpa awak. Kedua sistem tersebut memiliki peran sama pentingnya dalam sebuah pesawat tanpa awak. 
Tantangan utama pengembangan pesawat tanpa awak saat ini adalah daya jelajah dari pesawat tanpa awak. Salah satu penyebab terbatasnya daya jelajah adalah lemahnya sistem komunikasi antara pesawat dan ground station. Apabila sistem komunikasi antara pesawat dan ground station terputus, maka pesawat akan mengalami loss contact sehingga tidak bisa menginformasikan data dan sulit dikendalikan. Untuk mengatasi hilang kendali pada pesawat tanpa awak digunakanlah algoritma autonomous dengan berbekal gps dalam melakukan navigasi. Sistem ini dikenal dengan autopilot waypoint.

Penggunaan teknik autopilot waypoint untuk memperjauh daya jelajah dari pesawat tanpa awak bukan tanpa kekurangan, penggunaan autopilot waypoint, belum diimbangi dengan sistem downlink data jarak jauh sehingga informasi yang diambil dari pesawat belum dapat dikirimkan langsung ke ground station. Sistem downlink data pada pesawat tanpa awak memiliki peran yang penting, karena sistem ini yang menginformasikan posisi dan kondisi dari pesawat serta data yang dipantau. Dalam penelitian ini dirancang sebuah sistem downlink data yang diintegrasikan dengan kendali adaptif sehingga dapat menambah daya jelajah dari pesawat tanpa awak.

Sistem downlink data pada pesawat tanpa awak perlu dikembangkan untuk meningkatkan daya jelajah pesawat tanpa mengurangi kemampuan pesawat tanpa awak. Untuk mewujudkan gagasan tersebut, permasalahan yang harus diselesaikan dalam penelitian ini adalah mendapatkan desain dan membangun pilot plan sistem downlink data yang dapat mengirimkan informasi visual dan data sensor ke ground station dengan baik tanpa melanggar peraturan penggunaan frekuensi dan daya pancar gelombang radio sehingga bersifat legal dan dapat dikembangkan ke sistem yang lebih luas.

Penelitian ini dilakukan dengan tujuan untuk mendapatkan rancangan dan pilot plan sistem downlink data yang dikombinasikan dengan kendali adaptif sehingga tercipta perangkat downlink data cerdas yang dapat meningkatkan daya jelajah pesawat tanpa awak. Penelitian algoritma adaptif untuk menangani noise pada gps telah dilakukan sebelumnya.

\section{Metode}

Tujuan dari kegiatan penelitian tahun kedua adalah mendapatkan rancangan dan prototype perangkat keras untuk meningkatkan daya jangkau sistem downlink adaptif. Blok diagram sistem yang dibangun dalam tahun kedua dirangkum pada Gambar 1.

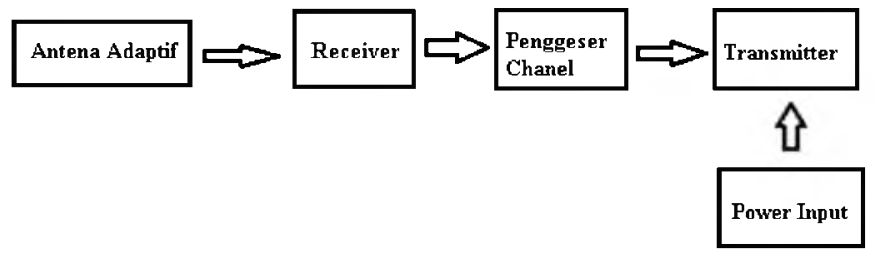

Gambar 1. Blok Diagram Sistem Pancar ulang Adaptif

Prototype yang sudah dibuat dapat dilihat pada Gambar 2 berikut ini.
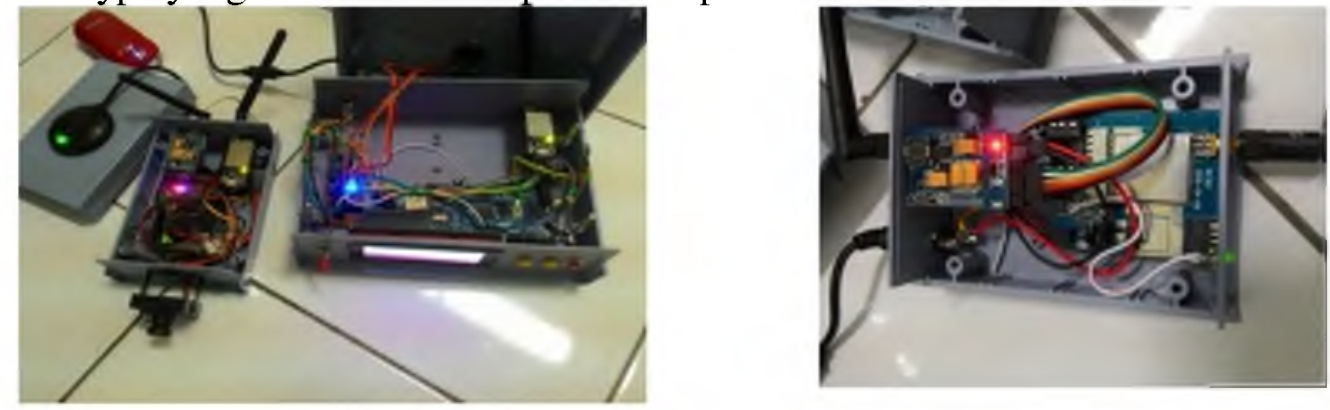

Gambar 2. Hasil Prototype Penelitian Tahun Ke 2. 
Algoritma yang dikembangkan dalam penelitian ini adalah algoritma Recursive Least Square dan Kalman Filter.

\section{Hasil dan Pembahasan}

Algoritma Estimasi yang telah dikembangkan adalah algoritma RLS dan KF. Dari simulasi yang dilakukan dapat disimpulkan bahwa kedua algoritma yang dirancang dapat mengestimasi dengan baik. Akan tetapi kedua algoritma tidak dapat diimplementasikan secara bersamaan, sehingga perbandingan algoritma perlu dilakukan. Perbandingan hasil estimasi algoritma ditunjukkan pada Gambar 3. Gambar 3 menunjukkan bahwa algoritma Kalman Filter lebih baik daripada algoritma RLS dalam mengestimasi.

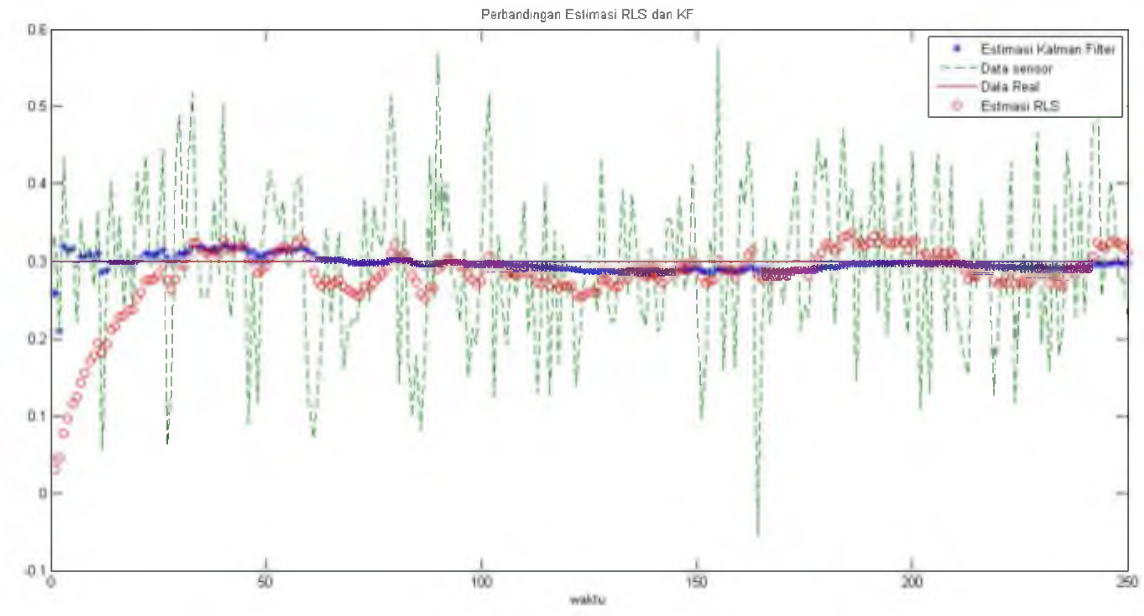

Gambar 3. Simulasi dengan Kalman Filter

Algoritma RLS dirangkum dalam persamaan 1. Sedangkan proses algoritma Kalman Filter dirangkum pada Gambar 4.

$$
\begin{aligned}
& \mathrm{G}(\mathrm{k})=\frac{\mathrm{P}(\mathrm{k}-1)}{1+\varphi(\mathrm{k}) \mathrm{P}(\mathrm{k}-1) \varphi(\mathrm{k})} \\
& \theta(\mathrm{k})=\theta(\mathrm{k}-1)+\mathrm{G}(\mathrm{k})[\mathrm{z}(\mathrm{k})-\varphi(\mathrm{k}) \theta(\mathrm{k} \\
& \quad \mathrm{P}(\mathrm{k})=\mathrm{P}(\mathrm{k}-1)-\mathrm{G}(\mathrm{k}) \varphi(\mathrm{k}) \mathrm{P}(\mathrm{k}-1)
\end{aligned}
$$

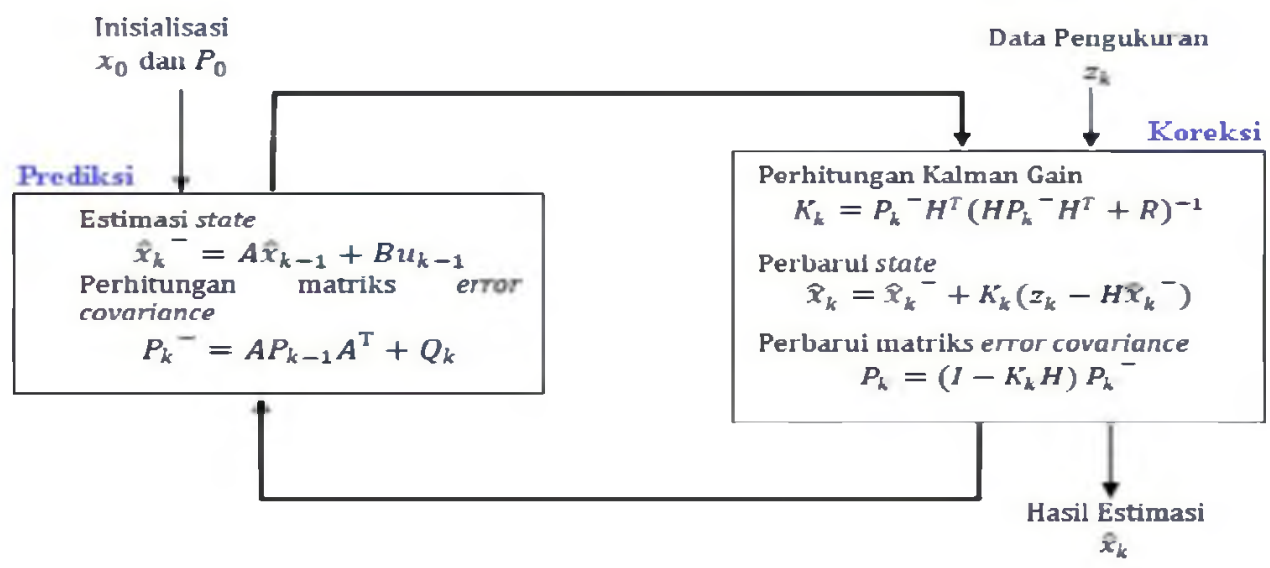

Gambar 4. Proses Algoritma Kalman Filter

Keterangan :

$=$ proses state pada waktu $\mathrm{k}$ 


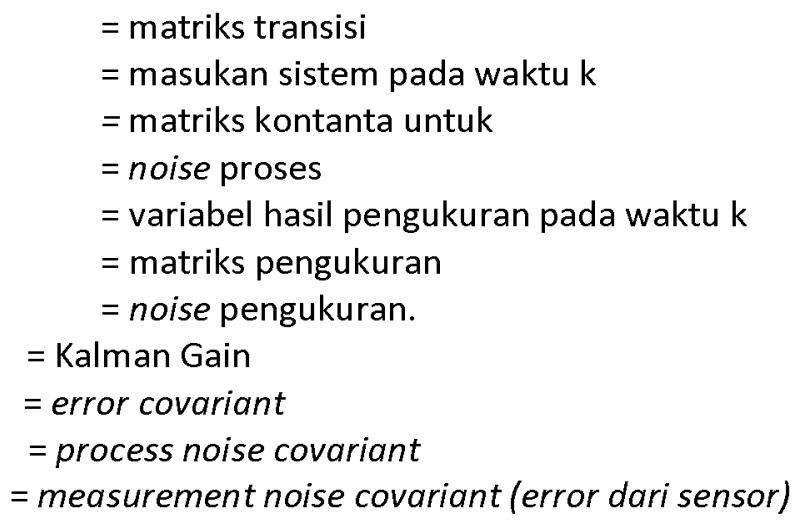

Analisis metode RLS dan KF menunjukkan bahwa pada algoritma KF memiliki keunggulan karena KF memiliki proses prediksi sedangkan RLS tidak memiliki. Kedua Algoritma juga memiliki proses koreksi yang prosesnya hampir sama. Algoritma KF dapat juga digunakan untuk mendesain sistem downlink yang tanpa menggunakan sinyal GPS. Dalam penelitian sebelumnya banyak dilakukan penelitian menggunakan kuat sinyal RSSI.

Persamaan proses yang digunakan merancang algoritma Kalman Filter adalah sebagai berikut,

$$
\left[=\left[\begin{array}{ccccccc}
1 & & 0,5 & & & \\
0 & 1 & & & 0 & \\
0 & 0 & 1 & & & \\
& & & 1 & & 0,5 \\
& 0 & & 0 & 1 & \\
& & & 0 & 0 & 1
\end{array}\right][.\right.
$$

Dari persamaan tersbut didapatkan matrik transisi A dan matrik state $\mathrm{X}$ adalah

$$
\begin{aligned}
& =\left[\begin{array}{lllllll}
1 & & 0,5 & & & \\
0 & 1 & & & 0 & \\
0 & 0 & 1 & & & \\
& & & 1 & & 0,5 \\
& 0 & & 0 & 1 & \\
&
\end{array}\right] . \\
&
\end{aligned}
$$

Karena sistem merupakan sistem observer maka matrik B dan input tidak dimasukkan dalam sistem. Output dari sistem dinyatakan dengan

$$
\left.=\begin{array}{cccccc}
1 & 0 & 0 & 0 & 0 & 0 \\
0 & 0 & 0 & 1 & 0 & 0
\end{array}\right] \text {. }
$$

Dari persamaan ouput diatas maka matrik pengukuran $\mathrm{H}$ dan data pengukuran $\quad$ yang dinyatakan dalam, 


$$
\begin{array}{lllllll}
= & 1 & 0 & 0 & 0 & 0 & 0 \\
& 0 & 0 & 0 & 1 & 0 & 0
\end{array}
$$

Nilai didapatkan dari proses algoritma1 atau 2, sedangkan didapatkan dari sensor.

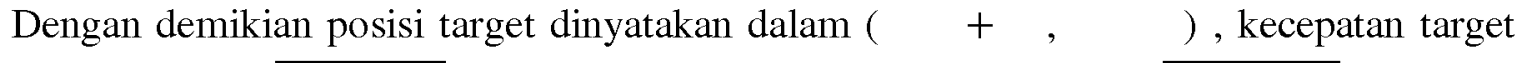
dinyatakan dalam $+\frac{+}{+}$ dan percepatan target dinyatakan dalam

\section{Kesimpulan}

Dari hasil simulasi yang dilakukan dapat disimpulkan bahwa Kalman Filter merupakan Algoritma Terbaik dalam mendesain sebuah sistem downlink adaptif.

\section{Daftar Pustaka}

J. W. Chaffee and J. S. Abel, "The GPS filtering problem," Position Location and Navigation Symposium, 1992. Record. 500 Years After Columbus - Navigation Challenges of Tomorrow. IEEE PLANS '92., IEEE. pp. 12-20, 1992.

C. Hide, T. Moore, and M. Smith, "Adaptive Kalman filtering algorithms for integrating GPS and low cost INS," Position Location and Navigation Symposium, 2004. PLANS 2004. pp. 227-233, 2004.

X. Mao, M. Wada, and H. Hashimoto, "Nonlinear filtering algorithms for GPS using pseudorange and Doppler shift measurements," Intelligent Transportation Systems, 2002. Proceedings. The IEEE 5th International Conference on. pp. 914-919, 2002.

I. M. Taylor and M. A. Labrador, "Improving the energy consumption in mobile phones by filtering noisy GPS fixes with modified Kalman filters," Wireless Communications and Networking Conference (WCNC), 2011 IEEE. pp. 2006-2011, 2011.

L. Wu, H. Ma, W. Ding, Q. Hu, G. Zhang, and D. Lu, "Study of GPS Data De-Noising Method Based on Wavelet and Kalman Filtering," Circuits, Communications and System (PACCS), 2011 Third Pacific-Asia Conference on. pp. 1-3, 2011.

S. Yamaguchi and T. Tanaka, "GPS Standard Positioning using Kalman filter," SICE-ICASE, 2006. International Joint Conference. pp. 1351-1354, 2006.

M. Zahaby, P. Gaonjur, and S. Farajian, "Location tracking in GPS using Kalman Filter through SMS," EUROCON 2009, EUROCON '09. IEEE. pp. 1707-1711, 2009.

Y.-S. Chen, T.-L. Chin, and Y.-C. Huang, "Collaborative localization in Wireless Sensor Networks based on dependable RSSI," Wireless Personal Multimedia Communications (WPMC), 2012 15th International Symposium on. pp. 341-347, 2012.

Z. Fang, Z. Zhao, D. Geng, Y. Xuan, L. Du, and X. Cui, "RSSI variability characterization and calibration method in wireless sensor network," Information and Automation (ICIA), 2010 IEEE International Conference on. pp. 1532-1537, 2010.

K. Heurtefeux and F. Valois, "Is RSSI a Good Choice for Localization in Wireless Sensor Network?," Advanced Information Networking and Applications (AINA), 2012 IEEE 26th International Conference on. pp. 732-739, 2012.

M. S. Hossen, M. K. B. Kamal, and M. S. Rahman, "Consistency analysis of RSSI measurement for distance estimation of Wireless Sensor nodes," Computer and Information Technology (ICCIT), 2012 15th International Conference on. pp. 290294, 2012.

P. K. Sahu, E. H.-K. Wu, and J. Sahoo, "DuRT: Dual RSSI Trend Based Localization for Wireless Sensor Networks," Sensors Journal, IEEE, vol. 13, no. 8. pp. 3115-3123, 
2013.

R.-H. Wu, Y.-H. Lee, H.-W. Tseng, Y.-G. Jan, and M.-H. Chuang, "Study of characteristics of RSSI signal," Industrial Technology, 2008. ICIT 2008. IEEE International Conference on. pp. 1-3, 2008.

Z. Zhang and D. Chen, "An improved RSSI-based centroid localization algorithm in wireless sensor networks," Computer Science and Service System (CSSS), 2011 International Conference on. pp. 3008-3011, 2011.

J. Y. Zhu, A. X. Zheng, J. Xu, and V. O. K. Li, "Spatio-temporal (S-T) similarity model for constructing WIFI-based RSSI fingerprinting map for indoor localization," Indoor Positioning and Indoor Navigation (IPIN), 2014 International Conference on. pp. 678-684, 2014. 